\title{
Study on the Economic Competitiveness Evaluation of Coastal Counties: Example as Liaoning Province
}

\author{
Qiang Mao \\ School of Management, Bohai University, Jinzhou 121013, China. \\ maoqiang_163@163.com
}

Keywords: Economic competitiveness; Competitiveness evaluation; Coastal counties

\begin{abstract}
The competitiveness of coastal county is an important area of study on regional competitiveness, and evaluation study on county economy is important basis and foundation to improve the competitiveness of coastal county economy. Based on a brief description of literature review, a method based on stakeholders' perspective is proposed to solve the competitiveness evaluation problem. In addition, the effectiveness of the proposed method is illustrated by the example as Liaoning province. Finally, some countermeasures are proposed to promote coastal county economy according the evaluation result and characteristics.
\end{abstract}

\section{Introduction}

Due to convenient transportation conditions for international trade, coastal counties get prosperity for trading with the world and will be easy to form manufacturing bases for processing trade. Many scholars are attracted to the research of economic competitiveness evaluation for its widely application background. Liu(2013) established evaluation index system of county economy for Tangshan, and proposed a method for county economy evaluation based on factor analysis [1]. $\mathrm{He}(2014)$ designed evaluation index system based on the perspective of economy development demand in county level, and analyzed the supporting ability of science and technology in Anhui by means of analytic hierarchy process(AHP) [2].Above mentioned methods have each superiority, but evaluation results rely too much on experts' preference. Evaluation objects are considered as passive objects in the above evaluation problems, while evaluation objects always have more complete evaluation information. In order to highlight the democracy of evaluation process and make full use of evaluation information of the object itself, many scholars proposed new methods [3, 4, 5]. Yi(2007) proposed a multi-attribute decision-making method indicating self-determination, which is based on weights non-dictatorship and competitive view optimization principle [6]. Li et al. (2012) proposed an objective self-determining evaluation method based on collaborative perspective, which can be used to solve interval number comprehensive evaluation problem [7]. Based on the models above, a method based on stakeholders' perspective is proposed to solve the competitiveness evaluation problem of Liaoning province.

\section{Evaluation Model}

Classic bargaining evaluation method is based on a multi-index evaluation system with evaluation object $\boldsymbol{O}=\left(o_{1}, o_{2}, \ldots, o_{n}\right)$ and evaluation index $\boldsymbol{X}=\left(x_{1}, x_{2}, \ldots, x_{m}\right)$. The index observed value $x_{i j}=x_{j}\left(o_{i}\right)$ $(i=1,2, \ldots, n ; j=1,2, \ldots, m)$ is objective existence, and an $n \times m$ observed value matrix $\boldsymbol{A}$ can be constructed as follows: $\boldsymbol{A}=\left[x_{i j}\right]_{n \times m}=\left[\begin{array}{cccc}x_{11} & x_{12} & \mathrm{~L} & x_{1 m} \\ x_{21} & x_{22} & \mathrm{~L} & x_{2 m} \\ \mathrm{M} & \mathrm{M} & \mathrm{M} & \mathrm{M} \\ x_{n 1} & x_{n 2} & \mathrm{~L} & x_{n m}\end{array}\right]$. Let $y_{i}$ be evaluation value of $o_{i}$, and the credible degree of comprehensive evaluation results is directly relates to the index weight.

We know that if one row vector is closely to another one in evaluation matrix $\boldsymbol{A}$, then the two evaluated objects could have more common interests. Based on the aforementioned analysis, we give definition of benefit correlation coefficient from the view of proximity of vector. 
Definition 1: Let $r_{i i}$, be benefit correlation coefficient between evaluated object $o_{i}$ and evaluated object $o_{i}$, and benefit correlation coefficient is given by

$$
r_{i i^{\prime}}=x_{i} \cdot x_{i^{\prime}} /\left\|x_{i}\right\| \cdot\left\|x_{i^{\prime}}\right\|, i, i^{\prime}=1,2, \ldots, n
$$

Where $\boldsymbol{x}_{i}=\left(x_{i 1}, x_{i 2}, \ldots, x_{i m}\right)$ is the row vector of matrix $\boldsymbol{A}$, and $\left\|x_{i}\right\|$ is the norm of $\boldsymbol{x}_{i}$. If the data of matrix $\boldsymbol{A}$ has been normalized, then $r_{i i}, \in[0,1]$. By definition 1, we know that the bigger the $r_{i i}$, is, the more benefits evaluated objects get from the cooperation.

Definition 2: Let $c_{i i}$, be net benefit coefficient between evaluated object $o_{i}$ and evaluated object $o_{i}$, and net benefit coefficient is given by

$$
c_{i i}=r_{i i},-\left(1-r_{i i},\right)=2 r_{i i},-1
$$

The Eq. 2 represents net benefit between evaluated object $o_{i}$ and evaluated object $o_{i}$, if they cooperate with each other. Obviously, $c_{i i}, \in[0,1]$. When $c_{i i}>0$, cooperation between evaluated object $o_{i}$ and evaluated object $o_{i}$, does not more harm than good. When $c_{i i}=0$, cooperation brings same pros and cons. When $c_{i i},<0$, cooperation does more harm than good, and evaluated object $o_{i}$ is a competitor for evaluated object $o_{i}$ '.

Suppose each evaluated objects as independent agents, then they want to highlight their own advantages and maximize their own interests as much as possible. In general, each stakeholder has some similar advantages, thus when an evaluated object highlights advantages of stakeholders, it also highlight its own advantages. So we suppose that each evaluation subject not only try to highlight its own inherent advantages, but also take advantage of the stakeholders to expand their advantage as much as possible.

According to the assumption that we can obtain calculation model of index bargaining weight by

$$
\max \sum_{i^{\prime}=1}^{n} c_{i i^{\prime}} \sum_{j=1}^{m} x_{i j} w_{j}^{(i)}
$$

where $w_{j}^{(i)}$ is index weight value from the perspective of evaluated object $\mathrm{o}_{i}$.

By literature [8], the index weight and evaluation value can be determined.

\section{Application of the Evaluation Model}

According to the literature [9], the evaluation indices and evaluation objects can be determined, and the evaluation index value can be obtained by literature [10]. In this case, there are six evaluation indices: gross regional domestic product $\left(x_{1}\right)$, total income of public Finance \& Budgeting $\left(x_{2}\right)$, total retail sales of consumer goods $\left(x_{3}\right)$, total export $\left(x_{4}\right)$, incoming overseas capital in place $\left(x_{5}\right)$, and gross fixed asset formation $\left(x_{6}\right)$. The date unit of $x_{1}, x_{2}, x_{3}, x_{6}$ are ten thousand yuan, and the date unit of $x_{4}, x_{5}$ are ten thousand dollar. There are twenty-three coastal counties: Ganjingzi $\left(o_{1}\right)$, Lvshunkou $\left(o_{2}\right)$, Jinzhou $\left(o_{3}\right)$, Changhai $\left(o_{4}\right)$, Wafangdian $\left(o_{5}\right)$, Pulandian $\left(o_{6}\right)$, Zhuanghe $\left(o_{7}\right)$, Zhenan $\left(o_{8}\right)$, Donggang $\left(o_{9}\right)$, Bayuquan $\left(o_{10}\right)$, Laobian $\left(o_{11}\right)$, Gaizhou $\left(o_{12}\right)$, Dashiqiao $\left(o_{13}\right)$, Shuangtaizi $\left(o_{14}\right)$, Xinglongtai $\left(o_{15}\right)$, Dawa $\left(o_{16}\right)$, Panshan $\left(o_{17}\right)$, Taihe $\left(o_{18}\right)$, Linghai $\left(o_{19}\right)$, Lianshan $\left(o_{20}\right)$, Longgang $\left(o_{21}\right)$, Suizhong $\left(o_{22}\right)$, Xingcheng $\left(o_{23}\right)$. The index data is shown in Table 1 .

According to the evaluation model, the comprehensive evaluation result can be obtained, $\boldsymbol{y}=\left[y_{1}\right.$, $\left.y_{2}, \ldots, y_{\mathrm{n}}\right]=[0.339,0.133,0.597,0.010,0.357,0.238,0.206,0.034,0.161,0.182,0.116,0.094,0.139$, $0.022,0.215,0.276,0.140,0.039,0.121,0.077,0.045,0.087,0.085]$. The economic competitiveness rank of coastal counties is shown in Table 2. 
Table 1 Related economic data of coastal counties in 2014

\begin{tabular}{|c|cccccc|}
\hline & $x_{1}$ & $x_{2}$ & $x_{3}$ & $x_{4}$ & $x_{5}$ & $x_{6}$ \\
\hline$o_{1}$ & 9635337 & 475311 & 7895253 & 4639753 & 102600 & 449935 \\
$o_{2}$ & 2840156 & 355196 & 4226611 & 690132 & 38550 & 120001 \\
$o_{3}$ & 16611661 & 1034143 & 15435839 & 3798479 & 429000 & 1013034 \\
$o_{4}$ & 892955 & 48123 & 502047 & 135491 & 11000 & 826 \\
$o_{5}$ & 10227642 & 728145 & 10849284 & 1860463 & 202421 & 64500 \\
$\ldots$ & $\ldots$ & $\ldots$ & $\ldots$ & $\ldots$ & $\ldots$ & $\ldots$ \\
$o_{23}$ & 1281312 & 135000 & 716707 & 12000 & 11014 & 1506825 \\
\hline
\end{tabular}

Table 2 The economic competitiveness rank of coastal counties

\begin{tabular}{|c|ccccc|}
\hline $\begin{array}{c}\text { coastal } \\
\text { counties }\end{array}$ & rank & $\begin{array}{c}\text { coastal } \\
\text { counties }\end{array}$ & rank & $\begin{array}{c}\text { coastal } \\
\text { counties }\end{array}$ & rank \\
\hline$o_{1}$ & 3 & $o_{9}$ & 9 & $o_{17}$ & 10 \\
$o_{2}$ & 12 & $o_{10}$ & 8 & $o_{18}$ & 20 \\
$o_{3}$ & 1 & $o_{11}$ & 14 & $o_{19}$ & 13 \\
$o_{4}$ & 23 & $o_{12}$ & 15 & $o_{20}$ & 18 \\
$o_{5}$ & 2 & $o_{13}$ & 11 & $o_{21}$ & 19 \\
$o_{6}$ & 5 & $o_{14}$ & 22 & $o_{22}$ & 16 \\
$o_{7}$ & 7 & $o_{15}$ & 6 & $o_{23}$ & 17 \\
$o_{8}$ & 21 & $o_{16}$ & 4 & & \\
\hline
\end{tabular}

\section{Conclusion}

The paper introduced the ideas of self-determining evaluation to economic competitiveness evaluation problem, and the method can reflect the subject status of each coastal county. According to the evaluation result, Jinzhou, Wafangdian and Ganjingzi develop better, and the other coastal counties still have resistance to enhance economic power, they urgently need operational measures to improve economic competitiveness.

First, each coastal county should promote structural adjustment of agricultural supply, build national modern agricultural demonstration zone, and develop green agriculture, circular agriculture, characteristic agriculture and brand agriculture.

Second, each coastal county should strengthen agricultural scientific and technological innovation, promote agricultural mechanization, prevention-control animal and plant diseases at their source.

Third, each coastal county should build specialized industrial base and agricultural products processing base, improve the level of marketization of coastal counties. 


\section{References}

[1] J. S. Liu, D. H. Zhao: Journal of Hebei United University(Social Science Edition), Vol. 13 (2013) No.5, p.50.(In Chinese)

[2] W. H. He, M. Liang and D. S. Yang: Journal of Anhui Administration Institute, Vol. 5 (2014) No.23, p.50.(In Chinese)

[3] Y. J. Guo: Theory, method and application of comprehensive evaluation (Science Press, China 2007) , p.165.(In Chinese)

[4] X. Chen, Z. P. Fan: Systems Engineering-Theory \& Practice, Vol. 27 (2007) No.2, p.27. (In Chinese)

[5] Z. S. Xu, X. Q. Cai:International Journal of International Journal of Intelligent Systems, Vol.25(2010) No.6, p.489.

[6] P. T. Yi, Y. J. Guo: Control and Decision, Vol. 22 (2007) No.11, p.1259.(In Chinese)

[7] W. W. Li, Y. J. Guo, P. T. Yi and Z. Y. He: Journal of Systems \& Management, Vol. 21 (2012) No.3, p.378.(In Chinese)

[8] Q. Mao, Y. J. Guo and Y. M. Guo: Systems Engineering and Electronics, Vol. 35 (2013) No.5, p.1008.(In Chinese)

[9] Y. D. Yang, Y. L. Jin: Development Research Report of Liaoning Coastal Economic Belf (Economic Science Press, China 2013) , p.22.(In Chinese)

[10]Liaoning Statistics Institute: Liaoning Statistical Yearbook (2015) (China Statistics Press, China 2015) , p.1.(In Chinese) 